\title{
How Latina mothers navigate a 'food swamp' to feed their children: a photovoice approach
}

\author{
Uriyoán Colón-Ramos ${ }^{1, *}$, Rafael Monge-Rojas ${ }^{2}$, Elena Cremm ${ }^{3}$, Ivonne M Rivera ${ }^{4}$, \\ Elizabeth L Andrade ${ }^{5}$ and Mark C Edberg ${ }^{5}$ \\ 'Department of Global Health, Milken Institute School of Public Health, George Washington University, Washington, \\ DC 20037, USA: ${ }^{2}$ Costa Rican Institute for Research and Education on Nutrition and Health (INCIENSA), Ministry of \\ Health, Tres Ríos, Costa Rica: ${ }^{3}$ Independent Consultant, Lower Hutt, New Zealand: ${ }^{4}$ Rivera Group, Washington, DC, \\ USA: ${ }^{5}$ Department of Prevention and Community Health, Milken Institute School of Public Health, George \\ Washington University, Washington, DC, USA
}

Submitted 28 January 2017: Final revision received 27 March 2017: Accepted 3 April 2017: First published online 18 May 2017

\begin{abstract}
Objective: To understand how mothers who recently migrated from Central America to the USA feed their children in a neighbourhood saturated with unhealthful food choices ('food swamp') and to formulate a mother-driven plan of action to facilitate their acquisition of foods.

Design/Setting/Subjects: We purposively sampled mothers with children $(<10$ years old) who were recent immigrants/refugees from Central America and lived in a 'food swamp' neighbourhood. We used the photovoice approach to elicit textual data from thirty in-depth interviews, a participatory workshop, and visual data from photographs. Analyses were guided by the Social Ecological Framework and Social Cognitive Theory to identify barriers, facilitators and strategies that support parents in feeding their children.

Results: Mothers valued foods that they considered to be 'traditional' and 'healthful'. They navigated their food retail environment looking for these foods (of good quality and well-priced). Food values were reinforced by pre-migration food customs and culture, health professionals' advice and, in some cases, by the desire to avoid conflict with their children. The neighbourhood food environment could directly influence children's food preferences and often created conflict between what the child wanted to eat and the foods that mothers valued. Mothers in this 'food swamp' wanted to be engaged in addressing the selection of foods offered in schools and in neighbourhood food venues to reflect their own food values. Conclusions: These mothers' feeding choices were influenced directly by their food values, and indirectly by the neighbourhood and school food environments via their children's preferences.
\end{abstract}

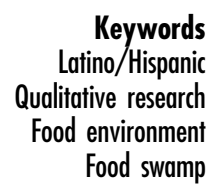

Hispanics/Latinos are the largest minority ethnic group in the USA and a relatively young population that presents increased burden for cardiovascular risk factors, including overweight and obesity $^{(1-4)}$. Over the past 20 years, the percentage of overweight Latino youth in the USA has approximately doubled $^{(5)}$. If unaddressed, these rates will lead to devastating consequences, including decreased quality of life and increased mortality and health-care costs related to preventable CVD, type 2 diabetes mellitus and certain cancers $^{(6)}$.

Higher rates of obesity are found among children living in low-income neighbourhoods ${ }^{(7,8)}$. These neighbourhoods often lack access to foods of high nutritional quality ${ }^{(8,9)}$. Federal and local initiatives have aimed at increasing economic and/or geographical access to healthful foods as one step in the process of improving diets and lowering the burden of obesity in high-risk populations ${ }^{(10-12)}$. However, there is limited evidence on the effectiveness of these strategies in increasing consumption of healthful foods in the USA ${ }^{(13,14)}$, particularly among children. Large longitudinal studies have not found an association between the neighbourhood food environment and foods available at home, children's diet, BMI or obesity ${ }^{(15-20)}$.

This disagreement in findings could be partly related to a gap in knowledge about how primary caregivers make feeding decisions in the context of neighbourhood food availability. Food choices are determined by a complex web of factors ${ }^{(14,21-26)}$. There is a critical need to provide conceptual clarity on how food environments may shape these choices among primary caregivers of children ${ }^{(27-29)}$. The present study aimed to deepen our understanding of what makes it easier or harder for Latina mothers to feed 
their children healthy foods, with an emphasis on the reciprocal relationship between mothers' feeding decisions and a neighbourhood food environment saturated with unhealthy options.

\section{Methods}

We used the photovoice methodology, a participatory qualitative research method, to elicit participants' documentation of their lived realities through photographs ${ }^{(30-32)}$ and to participate in a critical dialogue to recognize the causes of community-centric problems and identify possible solutions. We also conducted a culminating workshop whereby participants met to share their photos and to identify steps to transform their perspectives into action ${ }^{(30-33)}$.

\section{Study setting}

The study was conducted in a largely Latino immigrant community located in the Washington, DC, metropolitan area. The resident population ( $n$ 20675) is almost $80 \%$ Hispanic and almost $68 \%$ are foreign-born in Central American countries (primarily El Salvador and Guatemala). The community is mostly low-income, with almost one in four children living in poverty ${ }^{(34)}$. The region where the target population is based is saturated with food options, with $95 \%$ of adults in the community reporting a grocery store in the neighbourhood; many of these grocery stores cater specifically to Latinos. Although there is a variety of food establishments, $71 \%$ of them are fast-food restaurants ${ }^{(35,36)}$, suggesting that this community is a 'food swamp' or a geographic area with disproportionate access to energy-dense, nutrient-poor foods ${ }^{(37,38)}$.

The community is home to a $>12$-year-old communityacademic partnership (Avance Center for the Advancement of Immigrant/Refugee Health) that is guided by an advisory board including residents, representatives from nongovernmental and private organizations, interest groups, and academics and teachers. The partnership recently became interested in addressing poor nutrition and access to healthful foods in the community ${ }^{(39)}$. The work described here is part of formative activities conducted to decide the specific actions that the partnership could focus on.

\section{Theoretical framework}

The approach and design of the present study were developed and refined during discussions with the community advisory board of the community-academic partnership. The framework integrates elements of Social Cognitive Theory within a social ecological perspective. Social Cognitive Theory provides a theoretical framework for understanding and describing the potential interaction between individuals engaging in health behaviours and their environments. The basic principle from this framework is the simultaneous influence between environmental, cognitive or personal and behavioural factors (reciprocal determinism). Among the key theoretical concepts of the Social Cognitive Theory are self-efficacy (confidence in abilities to perform a behaviour), behavioural capability (actual knowledge and ability to perform a behaviour), responses internal or external to a person that affect the likelihood of behavioural continuance (e.g. values, outcome expectations, social reinforcement and expectancies) and observational or vicarious learning (observation and reproduction of others' behaviours) ${ }^{(40,41)}$. We incorporated these factors into the context of a social ecological approach in which an individual is nested within a larger context of the home, social and neighbourhood food environments ${ }^{(10,42,43)}$.

\section{Sample population}

We purposively sampled Latina/Hispanic mothers who lived in this community, had been in the USA for less than 15 years and had at least one child under the age of 10 years. We chose the specific age range for children because they are often more dependent on what foods parents bring home to eat ${ }^{(44-46)}$.

\section{Study participants and recruitment}

We worked closely with a local data collector group that has over 20 years of experience working and living in this community, to identify fifteen mothers through word of mouth and community outreach activities. Each participant provided written informed consent and was encouraged to ask questions about the study before starting.

\section{Data collection}

Following the photovoice approach ${ }^{(30-32)}$, we collected qualitative (textual and visual) data via four activities: (i) an initial in-depth interview with each mother $(\sim 1 \mathrm{~h})$; (ii) photographs taken over a 3-4 d period by mothers; (iii) a second in-depth interview with each mother to discuss her photos and elicit explanatory comment ( $40 \mathrm{~min})$; and (iv) a summary of an action-oriented workshop during which all participants identified their priority areas and made collective recommendations for future programmes and activities $(2 \cdot 5 \mathrm{~h})$.

\section{Individual in-depth interviews and photographs}

The research team developed an open-ended interview guide that included questions on the activities carried out during a typical day ('Can you walk me through your typical day?'), as well as about factors perceived as barriers and facilitators to providing the foods that caregivers wanted to provide for their children (i.e. 'Some parents mention that the foods that they provide are not the foods that they would like to feed their children; do you feel that way? What would make it easier for you to provide the foods that you want for your kids?'). At the end of each interview, the researcher and the participant identified together the barriers and facilitators that emerged during 
the interview. The researcher then asked the participant to take photos over the next $3-4 \mathrm{~d}$ of those barriers and facilitators, and any additional ones. Participants were provided with a folder that included information about the study, along with photo-taking tips. We provided cameras, but most participants ( $n$ 14) preferred to take photos with their phones. Participants were reminded daily via text or phone calls to take pictures during the next 3-4d.

During the second individual interview, participants were asked to share their photos and to identify three or four favourite pictures that best represented what made it easier or harder to provide the foods that they wanted to provide for their child. Participants were asked to state what the photo showed, why they took it, and to provide an illustrative title and description for each favourite photo according to principles of storytelling and contextualization ${ }^{(47)}$.

\section{Culminating workshop}

After all interviews had been conducted, the research team printed and organized the participants' favourite photos along with captions and descriptions. All interviewees ( $n$ 15) also participated in the culminating workshop. At the workshop, which was facilitated by the local data collector group and the principal investigator, each mother was asked to present her favourite photos and captions as illustrations of the barriers and facilitators. Then, as a group, they were asked to list the common barriers and facilitators that they wished to discuss and identify the reasons why. Each participant was asked to put a sticker next to the listed barriers/facilitators that she wanted to take further action on. This prompted an open-ended discussion about their shared and prioritized barriers, facilitators and next action steps.

Data were collected between April and May of 2015. Meetings were conducted at a convenient time and place for participants, and all data collection activities were audio- or videotaped with the express permission of participants. All instruments and protocols were reviewed and approved by the Office of Human Research of the George Washington University. Participants received a monetary incentive after completing the interviews.

\section{Data analysis}

Audio recordings from thirty individual interviews and the workshop discussion with fifteen mothers were transcribed verbatim for analysis as textual data. The data analysis followed a multi-step, iterative coding process. As a first step, the principal investigator systematically coded all data deductively using the thematic categories from our theoretical framework that identify the various environments from the social ecological approach and constructs of the Social Cognitive Theory ${ }^{(10,41,42)}$. As a second step, a research assistant also analysed the data independently and in the same manner. During a third step, the research assistant and principal investigator met to discuss the codes and illustrative quotations that emerged from this process, resolve discrepancies, refine sub-codes, merge themes and ultimately create an agreed-upon coding scheme. A fourth step was to review the photographs and their accompanying descriptions along with the textual data from the culminating workshop discussions using both the initial codebook and allowing for additional themes to emerge. The draft codebook was continuously revised and refined. Throughout this process, we also shared and discussed findings and interpretations with the community advisory board in order to identify alternative explanations from those derived, and to assess if our findings had identified salient issues according to the perceptions of our community advisory board members. This reflexive and communal exercise also allowed us to conceptualize the relationships between emerging themes.

\section{Results}

We present the findings of recurrent themes that emerged among a majority of mothers or that held a prominent place during the culminating workshop discussion. These themes are organized in tables according to the subthemes that emerged in all textual data, sometimes reinforced by visual data from photographs.

\section{Home environment: what caregivers are feeding their children}

Data from the in-depth interviews, the culminating workshop discussion and the photographs point to three categories of foods that mothers valued and wanted to feed their children: traditional foods, water, and fruits and vegetables (Table 1; sub-themes 1·1a-1·1c). Traditional foods were dishes that the mothers tied to their country of origin, such as soups and prepared dishes with rice, tortillas, Central American cheese and eggs. Mothers perceived that these foods were more healthful and therefore valued them more (internal reinforcement). They expected positive health outcomes from giving these foods to their children (outcome expectations). Traditional foods were also valued because, through preparing them, mothers reinforced a tie between their children (born and raised in the USA) and their own countries of origin.

During the interviews and discussions, mothers described their child feeding strategies based on their knowledge (behavioural capability) and outcome expectations. Some mothers decided themselves what the children would eat (Table 1; sub-theme 1.2a) and limited the child's exposure to 'outside' foods (Table 1; sub-theme 1.3a), while other mothers made the desired foods available in their homes and presented them in an appealing way to the children (Table 1; sub-themes 1.3b and 1.3c).

Other mothers, expecting negative responses from enforcing a menu that their children may not value, were then more permissive in the foods that they allowed at home. They allowed the children to decide, or at least influence, what was put on the table in order to avoid 
Table 1 Home environment: what mothers are feeding their children. Data collected from thirty in-depth interviews, a participatory workshop and a photovoice approach among Latina mothers with <10-year-old children living in a 'food swamp' in the Washington, DC, metropolitan area, April-May 2015

Sub-themes Illustrative quotes

1.1. What mothers want to feed their children 1.1a. Traditional foods

1.1b. Water

1.1c. Fruits and vegetables

1.2. Feeding strategies

1.2a. Parents decide what the children eat

$1 \cdot 2 b$. Children decide what they will eat or drink

1.3. Facilitator: exposure to foods

1.3a. Exposing kids to foods: mothers reinstate traditional Latin foods over 'American' foods

1.3b. Exposing kids to foods: preparation

1.3c. Exposing kids to foods: home availability

1.4. Barrier: exposure to 'American foods'
'Teaching my children to cook. I want to teach my children to cook typical foods of our culture.' (Caption from photograph for photovoice)

'You are able to prepare the food in your own way, and you know what it is made of and that it is natural.'

'El agua es vida. Water is life. Because of many diseases and motives. We cannot waste the opportunity to drink water and avoid obesity.' (Caption from photograph for photovoice)

'I buy water, water, water, water ... bottled water. I have accustomed them [children] to drink water because it is more healthful.' (Culminating workshop discussion)

'I like to give her more things of fruits because they are good for her. And the vegetables.'

'They don't say “I don't want that." No. That is what they eat. What is served to them is what they eat.'

'The easiest work for the mom is to offer the foods that they like the most. I do not complicate my life giving them something that they do not like.' (Speaking about a photograph)

'My kids are not used to eating out; they don't eat foods like pizza. They eat tortillas, beans and rice. They don't eat foods you buy from outside.'

'Sometimes we make a butterfly out of oranges, strawberries, things like that. They love it. After we work to make it, then they eat it.'

'If they see fruit on the table, they are always picking and eating.'

'I don't buy juices or sodas; I only keep water at home.'

'I try to make them chicken breast and rice, and so I give it to them. [but] they want pizza, hamburger and doughnuts. Doughnuts, they prefer to go to Dunkin Donuts.'

'So then sometimes I don't even cook because I say "they'll just leave it there", it is better that we buy fast food.' conflict (Table 1; sub-theme 1.2b). For example, some mothers described that the foods that they offered at home (traditional foods, vegetables, fruit, water) were rejected by the children in favour of 'outside' foods such as pizza, French fries and fried chicken (Table 1; sub-theme 1.4). This led to frustration, as one mother expressed, deterring her from cooking and pushing her to purchase ready-toeat foods available in fast-food outlets. These data suggest that for mothers who valued family cohesion over other aspects of foods (e.g. healthfulness or tradition), the children's preferences could then influence what the mothers fed them (reciprocal determinism).

\section{Social environment: the roles of work and the nuclear family in deciding what to feed their children}

The majority of mothers had limited social networks that included the nuclear family (husbands, children, mother-inlaw) and neighbours, some of whom they paid to take care of their young children (Table 2; sub-theme 2.1). Mothers relied on the assets that these limited networks afforded them in order to acquire resources to feed their children. For example, mothers described how their participation in the informal local economy, selling ice creams or other items, helped them make ends meet. This sub-theme was also described as a source of concern, because these informal work activities did not provide sufficient economic stability to systematically cover their housing and utility bills. Housing and utility bills were discussed as being prioritized (out of necessity) over child or family nutrition (Table 2; sub-theme 2.2), altogether suggesting that the social environment provided few incentives to prioritize family or child nutrition over other needs.

\section{Neighbourbood physical environment: availability and access to specific foods and beverages in the neighbourbood}

This theme emerged only during the culminating workshop. In discussing where they obtained the foods portrayed in their photographs, mothers described how they had easy access to supermarkets and grocery stores that cater to the Latino population. This made it convenient for them to shop if they did not have a car (Table 3; subtheme $3 \cdot 1 \mathrm{a})$. The majority of mothers felt that there was a strong influence from the neighbourhood food environment to consume sugary drinks, because stores in the community are saturated with these beverages. According to these mothers, stores are oriented towards satisfying the preferences of Latinos who come from countries where sodas are popular, but the cost is prohibitive. As one 
Table 2 Social environment: the roles of work and the nuclear family in deciding what to feed their children. Data collected from thirty in-depth interviews, a participatory workshop and a photovoice approach among Latina mothers with $<10$-year-old children living in a 'food swamp' in the Washington, DC, metropolitan area, April-May 2015

\begin{tabular}{|c|c|}
\hline Sub-themes & Illustrative quotes \\
\hline \multicolumn{2}{|l|}{ 2.1. Mothers have limited social networks to rely upon } \\
\hline 2.1a. Neighbours & $\begin{array}{l}\text { 'I work from } 2 \text { a.m.; I get out at } 11 \text { a.m., and I come home and make food since } \\
\text { they are in school.' }\end{array}$ \\
\hline & $\begin{array}{l}\text { 'There is just the one other child who is not in school and others take care of him } \\
\text { for me.' }\end{array}$ \\
\hline 2.1b. Nuclear family & $\begin{array}{l}\text { 'Thank God that he is one of those men that are good for working and that have } \\
\text { always brought money home and responsible.' } \\
\text { 'And I also have my mother-in-law who sometimes helps me with food.' }\end{array}$ \\
\hline $\begin{array}{l}\text { 2.2. Informal work presents both a barrier and a } \\
\text { facilitator to feeding their children }\end{array}$ & $\begin{array}{l}\text { 'We all work. We take care of children in our houses; we sell things, and when } \\
\text { we do not have a fixed job with benefits, that worries us. But usually, } \\
\text { whenever a little job comes up, each one of us does it and we get ahead.' } \\
\text { (Culminating workshop discussion) }\end{array}$ \\
\hline
\end{tabular}

Table 3 Neighbourhood physical environment: availability and access to specific foods and beverages in the neighbourhood (theme emerged only during culminating workshop discussion). Data collected from thirty in-depth interviews, a participatory workshop and a photovoice approach among Latina mothers with <10-year-old children living in a 'food swamp' in the Washington, DC, metropolitan area, April-May 2015.

\begin{tabular}{|c|c|}
\hline Sub-themes & Illustrative quotes \\
\hline \multicolumn{2}{|l|}{$\begin{array}{l}\text { 3.1. Description of Latin stores and food availability in } \\
\text { those stores }\end{array}$} \\
\hline 3.1a. Proximity to stores & $\begin{array}{l}\text { 'Because we feel more comfortable in the Latin supermarket, but also } \\
\text { because it is close to us, because of transportation, it is more } \\
\text { convenient to go to Latin stores.' (In discussion about the various } \\
\text { supermarkets of the area and where they bought their foods) } \\
\text { 'Usually I go to the Latin store, but if I want to buy the fresh fruit, then I } \\
\text { have to wait to go to Costco. Then usually I have to wait until } \\
\text { Saturdays or Sundays for my husband to be home so that he can } \\
\text { take me.' }\end{array}$ \\
\hline \multirow[t]{2}{*}{ 3.1b. Food availability in Latin stores } & $\begin{array}{l}\text { 'In the stores they sell a lot of juices and sodas; because they are } \\
\text { there, there is consumption! They know we come from a country } \\
\text { where we consume Coca-Cola.' }\end{array}$ \\
\hline & $\begin{array}{l}\text { 'We have all this soda. In our own country, one buys what one needs } \\
\text { the most. Once in a while you drink one. However, here, there is } \\
\text { more access. They gift you a package of soda if you buy } \$ 50 \text { or } \\
\text { more in the Latin store.' }\end{array}$ \\
\hline \multirow[t]{3}{*}{$\begin{array}{l}\text { 3.2. Infrastructure for drinking-water (Sub-theme emerged } \\
\text { only as a discussion during culminating workshop) }\end{array}$} & $\begin{array}{l}\text { 'Because some say that tap water is more healthful than the other } \\
\text { one [bottled]. They have told me to give him [child] water, to give } \\
\text { him water from the tap. "I drink tap water and look at me," they say. } \\
\text { But tell me, if I open the tap, and it comes out yellow, should I drink } \\
\text { it or not?' }\end{array}$ \\
\hline & $\begin{array}{l}\text { 'One day, a water inspector came to my house selling water filters. He } \\
\text { did an experiment where he poured some drops of water and the } \\
\text { water turned automatically turned black.' }\end{array}$ \\
\hline & $\begin{array}{l}\text { 'I know that water here [in the USA] is recycled from everywhere all } \\
\text { the time. It is not like in our countries that it is a river and it runs. } \\
\text { Because there [in their countries] you practically see the lake, and } \\
\text { we go by and we know that the water passes there. Here, no. Here } \\
\text { [in the USA] the water is recycled from the sink, from the toilet all } \\
\text { that water runs and comes out again to your tap.' }\end{array}$ \\
\hline
\end{tabular}

Costco is a US warehouse that sells foods; it is also a chain.

mother explained, sodas were available and more affordable in the USA (Table 3; sub-theme 3·1b). These data suggest that a neighbourhood environment where these beverages are more available and affordable can externally reinforce the desire to consume these sugary drinks.

An important issue that arose concerned potential alternatives to sugary beverages, specifically water.
Although mothers wanted to provide water for their children to drink, they also expressed negative outcome expectations about tap water, considering it to be dirty and distasteful. This was linked to the perception that the physical environment of their neighbourhood was a barrier to drinking water (e.g. water utility, housing and water pipes) (Table 3; sub-theme 3.2). For example, although some mothers had been told that tap water 
Table 4 Macrosystem: national policies and programmes, customs and culture. Data collected from thirty in-depth interviews, a participatory workshop and a photovoice approach among Latina mothers with < 10-year-old children living in a 'food swamp' in the Washington, DC, metropolitan area, April-May 2015

Sub-themes Illustrative quotes

4.1. Pre-migration customs and food culture (emerged only during culminating workshop discussions)

4.1a. Foods in country are more delicious

'Always us, Latinos, would plant, and we had where to plant over there in our countries, so that we could make juices, whereas here [in USA], no. There's no place [to plant].' (Emerged only from culminating workshop discussion)

'There too [country of origin], the chicken was more delicious. The taste of the chicken is very different over there. Here they have those large chickens but they do not taste like anything.'

'When you are able to prepare the food in your own way, and you know what it is made of and that it is natural. It is not just reheated.'

4.1b. 'We come from a country where we consume 'Even I, at lunchtime, cannot drink water. It's the habit. I would love to lie and say Coca-Cola'

that I give them only water, but it is not true. It's the habit.'

'They know we come from a country where we consume Coca-Cola [...] Suddenly, one eats a certain food, and feels the need to drink a Coca-Cola. But when I was little, the soda was not something that you could buy every day.'

4.2. Health professionals' advice

'Since he was little he has suffered from having cavities. [...] he drank soda and juice $[. .$.$] the dentist told me "this boy had too many sweets." He has had his$ dental problems.'

'The doctor told my child that she has to eat healthier; that is when we started to eat dinner with more vegetables. The doctor said no sweets, no candies, no pizzas, no McDonalds.'

4.3. National programmes

4.3a. School feeding impedes mothers from providing 'She says "Mommy it's because the food from school I don't like it." I ask why healthful and traditional foods she doesn't like it she says "Because they give beans that are sweet and that chicken with barbeque. I don't like it."'

'In schools, it is difficult. [...] the milk has a horrible quantity of sugar because they give it to them of strawberry and chocolate.' (Excerpt from culminating workshop discussion)

4.3b. WIC programme

'They give us a bag of beans for each one [...] one carton of eggs, cheese, and from there I make pupusas.'

'I rarely buy broccoli and cauliflower [...] when they give me coupons for the farmers' market from WIC and that is when I take the opportunity to buy it for them.'

WIC, Special Supplemental Nutrition Program for Women, Infants, and Children.

was more healthful, they reported that the water in their homes often came out yellow or dirty because the homes in their neighbourhood had worse piping infrastructure than more affluent neighbourhoods. The low expectancies linked to tap water consumption were heightened by uncertainty about the origin of potable tap water in the USA. For example, mothers believed (erroneously) that tap water in the USA was recycled from the toilet and faucet - it is unclear from where this belief originates. In contrast, in their countries of origin, mothers trusted tap water because they saw the actual source of the water, often a river or a lake (Table 3; sub-theme 3.2).

\section{Macrosystem: national policies and programmes, customs and culture}

Three themes, all related to the macrosystem and characteristic of the reciprocal determinism proposed by the Social Cognitive Theory, were identified as factors that made it easier or more difficult for mothers to offer the foods that they valued for their children: (i) customs related to pre-migration food habits (a cultural and cognitive factor); (ii) health professionals' advice (behavioural practice); and (iii) the national nutrition and feeding programmes (policy-level environmental factor) (Table 4; sub-themes 4.1-4.3).

Customs and pre-migration culture, a theme that emerged during the culminating workshop, could influence which foods mothers valued based on their cultural roots and beliefs about healthfulness of these foods. Mothers described how foods tasted better in their country of origin than in the USA, and expressed concern about chemicals and preservatives in the foods commonly found in the USA (Table 4; sub-theme 4.1a). They wanted to transmit traditional food customs to their children and recreate the same feeding experiences from their home country.

The advice of health professionals had also shaped mothers' decisions on what to feed their families. Dentists, doctors and nutritionists advised mothers on what to eat in order to deal with family members' problems with diabetes, obesity, dental cavities and other ailments (Table 4; 
Table 5 Mesosystem: how mothers navigate the food environment. Data collected from thirty in-depth interviews, a participatory workshop and a photovoice approach among Latina mothers with <10-year-old children living in a 'food swamp' in the Washington, DC, metropolitan area, April-May 2015

\begin{tabular}{|c|c|}
\hline Sub-theme & Illustrative quotes \\
\hline \multicolumn{2}{|l|}{ 5.1. Deciding where they will buy the foods they want/need } \\
\hline \multirow{3}{*}{$\begin{array}{l}\text { 5.1a. Where are the foods that they 'need' available? } \\
\text { (Sub-theme emerged only during culminating } \\
\text { workshop discussion) }\end{array}$} & 'We all go to the Latin stores to get the rice, the beans, the [Central \\
\hline & $\begin{array}{l}\text { American] cheese, the [Central American] cream }[\ldots] \text { The things that } \\
\text { we do not need, then we find in Costco, Giant or Walmart.' }\end{array}$ \\
\hline & $\begin{array}{l}\text { 'We go to the Latin stores because it is more comfortable, because it is } \\
\text { lack of information. We cannot cook the things that are there at } \\
\text { Safeway and Giant.' }\end{array}$ \\
\hline \multirow[t]{3}{*}{$5.1 \mathrm{~b}$. Where are the foods that they 'need' well-priced? } & 'Safeway and Giant; no, no, no, that's where the rich people go \\
\hline & $\begin{array}{l}\text { [laughing]. They have Latin foods, but sometimes we find them } \\
\text { expensive.' (From culminating workshop discussion) }\end{array}$ \\
\hline & $\begin{array}{l}\text { 'I am buying this because it is on sale. But I buy two or three things a day, } \\
\text { or for the week.' }\end{array}$ \\
\hline \multirow[t]{2}{*}{ 5.1c. Where are the foods that they 'need' of better quality? } & $\begin{array}{l}\text { 'Well I go to the Aldi because I buy a lot of things there. And for meat I go } \\
\text { to the Mega, because I like it more fresh.' }\end{array}$ \\
\hline & $\begin{array}{l}\text { 'Because in the Latin stores they sell too many things that are spoiled: } \\
\text { fruits, meats, they do not have the control, the yoghurts are spoiled } \\
\text { sometimes.' (From culminating workshop discussion) }\end{array}$ \\
\hline \multirow[t]{2}{*}{ 5.1d. Buying in bulk } & $\begin{array}{l}\text { 'Sometimes I prefer to buy them in bulk. [...] } 25 \text { pound for the whole } \\
\text { month and a little for more.' }\end{array}$ \\
\hline & 'We go for the largest litre, for some juices for the kids, the largest litres.' \\
\hline \multirow[t]{3}{*}{ 5.1e. Adjusting diet at end of month } & 'A week after the famous rent comes is when one has to start to eat more \\
\hline & $\begin{array}{l}\text { differently }[\ldots] \text { we think about different types of foods that don't } \\
\text { incorporate too much meat or fish or nothing.' }\end{array}$ \\
\hline & $\begin{array}{l}\text { 'In that week before paying the rent, it is the sweets that are not put into } \\
\text { the basket.' }\end{array}$ \\
\hline
\end{tabular}

Giant, Aldi and Safeway are US supermarket brands with national chains. Costco and Walmart are warehouses that sell foods; they are also chains. Megastore is a local supermarket that targets Latinos by bringing foodstuffs from Latin America.

sub-theme 4.2). This suggests that health professionals' advice led to self-efficacy to provide a healthy diet and reinforced mothers' positive expected outcomes when serving fruits and vegetables, leaner cuts of meat, water and fewer sugary drinks. However, some practices that were tied to pre-migration food habits, such as having a sugary drink with each meal, were perceived as 'difficult to change', regardless of known health consequences (Table 4; sub-theme 4.1b). These data suggest that for those mothers there was a value conflict between the health aspects of a food and the pre-migration habits or cultural roots of the food. As noted earlier, the premigration habits related to sugary drink consumption were reinforced by a neighbourhood food environment in the USA that made sweet beverages more accessible and affordable.

In accordance with the above, the majority of mothers mentioned that the school feeding programme exposed the children to foods that they considered unhealthful or culturally inappropriate. They therefore compensated at home by feeding their children the traditional foods that they valued more (Table 4; sub-theme 4.3a). The Special Supplemental Nutrition Program for Women, Infants, and Children (WIC) facilitated mothers' feeding decisions because it gave out vouchers that allowed mothers to purchase fruits, vegetables and dairy products to prepare foods that they valued and could not otherwise afford (Table 4; sub-theme 4.3b). No other safety net programmes were mentioned.

\section{Mesosystem: how mothers navigate the neighbourbood food environment}

Since mothers had assigned values to specific foods that they wanted to provide for their children, they navigated the food retail environment looking for these foods. The characteristics of the neighbourhood food environment and the values that mothers had assigned to foods led to a complex dynamism at the time of procuring foods. Mothers navigated the neighbourhood food retail environment and decided where to shop based on availability, pricing and quality of foods that they had decided to value (Table 5; sub-themes $5 \cdot 1 \mathrm{a}-5 \cdot 1 \mathrm{c})$. For example, they went to the Latino stores to obtain items that were essential for the preparation of traditional foods (rice, beans, special creams and cheeses imported from their countries of origin) and that were unlikely to be found elsewhere.

As part of this reciprocal process, the mothers' selfcontrol regarding food expenditures influenced family eating behaviours. The majority of mothers described how they planned shopping according to their monthly or biweekly budgets, and adjusted their shopping strategies accordingly. For example, many would buy in bulk (Table 5; sub-theme 5.1d), stocking up on large quantities of non-perishables such as rice and oil. They resorted to different strategies to offset the negative expectancies of having unbalanced foodstuffs in their homes at the end of the budget period. For example, they: (i) stayed away from animal proteins such as meats and fish, and instead complemented the staples with beans; (ii) changed recipes 
Table 6 Actions from culminating workshop. Data collected from Latina mothers with $<10$-year-old children living in a 'food swamp' in the Washington, DC, metropolitan area, April-May 2015.

\begin{tabular}{|c|c|}
\hline Sub-themes & Illustrative quotes \\
\hline \multicolumn{2}{|l|}{ 6.1. Action items } \\
\hline $\begin{array}{l}\text { 6.1a. Address inequities in standards of } \\
\text { quality of foods in stores }\end{array}$ & $\begin{array}{l}\text { 'With a gringo [White American] they would never dare sell them things like that. If they put } \\
\text { something spoiled in the store, they will complain. For us ... the stores are not selling the } \\
\text { quality of food that we need. We all work, but if we organize ourselves ... if those stores } \\
\text { had regularization like Safeway and Costco have, they would not sell us those things.' }\end{array}$ \\
\hline $\begin{array}{l}\text { 6.1b. Have a voice in determining school } \\
\text { food environment }\end{array}$ & $\begin{array}{l}\text { 'They [schools] give them canned fruits, and fried foods. The milks are expired; the yoghurts, } \\
\text { expired. The milk has a horrible quantity of sugar because they give it to them in } \\
\text { strawberry and chocolate flavours. We need to advocate for the schools.' }\end{array}$ \\
\hline \multirow[t]{2}{*}{$\begin{array}{l}\text { 6.1c. Reinforce their knowledge about } \\
\text { healthful food choices }\end{array}$} & $\begin{array}{l}\text { 'For us, either they do not listen to us, or we do not have the information on what to do. [...] } \\
\text { They know that we are Latinos and that we go there looking for the least expensive. Then } \\
\text { there are us mothers who go for the cheapest, and we do not read. They take advantage } \\
\text { of us because one does not read.' }\end{array}$ \\
\hline & $\begin{array}{l}\text { 'Because some [Americans] say that tap water is more healthful than the other one [bottled]. } \\
\text { They have told me to give him [child] water, to give him water from the tap. "I drink tap } \\
\text { water and look at me," they say. Then, why [do they say that]?' }\end{array}$ \\
\hline
\end{tabular}

Safeway is a US supermarket brand with a national chain. Costco is a US warehouse that sells foods; it is also a chain.

to include less oil, which is expensive, and fewer perishables (also expensive); and (iii) bought only what was necessary and avoided sweets, desserts or non-perishable foods (Table 5; sub-theme 5.1e).

\section{Actions from culminating workshop}

The photovoice approach draws from an approach that uses critical reflection as a mechanism for discovery of social inequalities and emphasizes action to address these inequalities ${ }^{(32,47,48)}$. During the culminating workshop, mothers discussed what they would like to address to make it easier for them to feed their children and they emphasized three areas for action that triangulate the relationship between socio-environmental, personal and behavioural factors: (i) the neighbourhood food retail environment; (ii) the school food environment; and (iii) education and information (Table 6). Mothers hinted at a sense of injustice and inequity when discussing access to clean tap water for drinking and to quality foods in their neighbourhoods vis-à-vis more affluent, white-serving neighbourhoods. Nevertheless, mothers showed a strong self-determination and wanted the stores and schools to provide foods more in line with their food values. They suggested forming groups to advocate for: (i) improving the foods sold in Latino retail stores in their communities; (ii) learning about and influencing foods offered at lunch; and (iii) learning about how to make better choices and reinforce their own knowledge about healthful foods and beverages for their children.

\section{Summary of results}

We summarize the results in a refined conceptual framework (Fig. 1) that emerged from the relationships between the different themes and sub-themes in the present study. In all of the framework's segments, reciprocal determinism and external reinforcement between behaviours and environments play a key role. At home, mothers valued certain foods based on their outcome expectations (keeping traditions, healthfulness of foods and, in some cases, avoidance of conflict). Child feeding strategies then emerged based on their outcome expectations. Mothers navigated the neighbourhood food retail environment in order to find quality and affordable foods and beverages that they valued for their children (Segment A). For some mothers, child preferences also influenced mothers' food values, especially if mothers wanted to avoid the conflict caused by food preferences (Segment B). Child preferences could be directly influenced by exposure to foods in the neighbourhood and at schools (Segment C). Mothers' expected outcomes related to serving specific foods were reinforced by pre-migration food customs and habits and health professionals' advice (Segment E), and these, especially in the case of sugary drink consumption, were further reinforced by the availability and affordability of these foods in the neighbourhood food retail environment. The informal economy and national feeding/nutrition programmes facilitated the purchase of foods that the mothers valued (Segment D).

\section{Discussion}

In light of persistently increasing obesity and overweight rates among Latino children and adolescents, there is a need for conceptual clarity on how the physical food environment may shape feeding decisions among primary caregivers of children ${ }^{(49-51)}$. Our results contribute to the growing literature on how food shopping decisions are determined and support previous reports that describe how these decisions are determined by a complex network of factors beyond the physical food environment ${ }^{(14,21-26)}$.

Mothers navigated the neighbourhood food retail environment to procure the foods that they valued for their children. Our data suggested that these Latina mothers valued foods that they considered to be healthful and 'traditional' because of the positive expected outcomes from providing these foods. Other studies with varied 


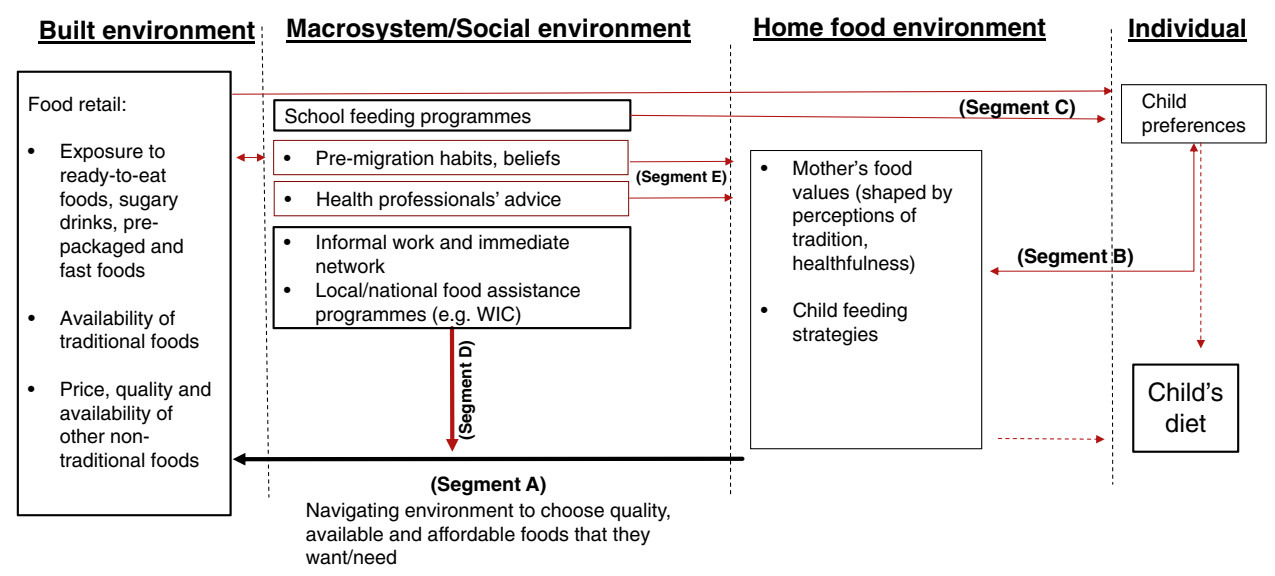

Fig. 1 Conceptual framework depicting the interactions between various environments and children's diets among Latinos in a food swamp (WIC, Special Supplemental Nutrition Program for Women, Infants, and Children)

Latino populations have reported similar findings that emphasize Latino parents' knowledge about, and desire to feed, healthful foods to their children ${ }^{(52-55)}$. These values could be influenced, at least in part, by the knowledge and degree of confidence or self-efficacy that the mothers felt about feeding these foods to their children.

Advice from health professionals can reinforce the confidence that mothers feel in improving dietary choices for their families. Health professionals' advice can contribute to mothers' knowledge of what is healthful to eat and what to feed their families, as well as to mothers' selfefficacy to take those actions. Others have reported that Latinos trust doctors' information slightly more than media sources of information or than family and friends ${ }^{(56)}$, even if they face numerous barriers to accessing formal health care $^{(57)}$. The findings from our study are somewhat surprising given the limited geographic access to clinics and hospitals in the community (a report from 2014 found that there are no paediatricians and medical specialists in the neighbourhood, and a very small number of primary caregivers; all families travel to neighbouring areas to get these medical services ${ }^{(36)}$ ). However, there are also outreach programmes from private health organizations and national programmes (e.g. doctors, nurses and other health practitioners through Federally Qualified Health Centers; nutritionists with WIC) that specifically target and try to reach Latinos via bilingual programmes and door-todoor visits of community health workers. Our results imply that engaging health professionals in this community to disseminate health and nutrition information has been, and may continue to be, a successful strategy to reach mothers and achieve better health outcomes.

Mothers' food values for offering 'healthful' or 'traditional' foods could be offset by conflicting child food preferences. The food choice literature explains this common phenomenon as clashing food values between family members ${ }^{(46,58)}$. Individuals tend to place values on foods and the position that a specific food holds within a value hierarchy may affect whether or not the food is consumed $^{(59)}$. For example, although mothers may want to introduce foods that they consider more healthful or 'traditional', these foods may not reflect the cultural identity or preference of their US-born children and therefore may not hold the same value for the children. This could produce conflict between family members. Conflict can also arise within individuals if two foods hold different competing values: for example, drinking water may have a positive 'healthful' value for mothers, but drinking sugary drinks with meals has a positive 'traditional' value that recalls cultural identity for mothers. Depending on the hierarchy between healthful and traditional values, a decision will be made. For those mothers who may place higher priority on sustaining stable and positive relationships, they will provide their children the foods that do not produce conflict at the expense of healthful foods.

Our findings also emphasize the reciprocal determinism between the environment, culture and social environments that leads to external and internal reinforcement of behaviours $^{(40,41)}$. For example, mothers' beliefs about the source of tap water in the USA were reinforced by the environment (yellow water coming out of the pipes) and resulted in behaviours (not providing tap water to their children). Similarly, exposure to foods at school and in the neighbourhood food retail outlets could have directly influenced the children's food preferences and possibly caused clashes in food values with their mothers, while also shaping what the mothers ultimately valued and decided to feed their children. The school feeding environment was of particular concern to the mothers because the children spend the majority of their day there $^{(60)}$ and the mothers had no influence and limited knowledge about the foods that were fed to their children during this time. Schools exposed the children to foods that mothers considered to be culturally inappropriate or unhealthful. These food choices presented to the children at school were thought to directly influence children's food preferences, thereby causing conflict at home. Evans and colleagues reported similar findings among 
Spanish-speaking Latino families (mostly Mexican) in Texas $^{(61)}$. Those families then made their traditional, culturally appropriate foods more available to their children at home. This is a missed opportunity for school feeding and the success of the Healthy Hunger Free Kids Act, which provides federal guidance on the quantity and quality of foods served at school. If parents or children dislike the foods provided at school, they may bring more snacks and foods from home to consume at school. Children who consume lunch or snacks brought from home tend to have worse diet quality than those who eat the school lunch ${ }^{(62)}$. Engaging parents and the student body as stakeholders in school-feeding decision making has been touted as a key factor to the success of school feeding programmes ${ }^{(63)}$.

Finally, mothers' reliance on their immediate social environment (nuclear family, neighbours) and national programmes like WIC made it easier for them to feed their children by either making foods more affordable or freeing their time to spend in informal economic activities in order to eventually be able to afford foods. Mothers' reliance on their nuclear families is not uncommon among Latin American families with strong feelings of familismo, a cultural value reflecting strong family attachment ${ }^{(64-66)}$. But their dependence on the nuclear family and immediate neighbours could also be due to difficulties in building and maintaining social ties, which have been reported as a common barrier to social support among recent immigrants ${ }^{(64,65,67)}$. First-generation Latina immigrants, for example, reportedly rely on a smaller set of social ties to meet their needs compared with second-generation Latinas ${ }^{(68)}$. In addition to language and cultural barriers, socio-economic pressures to make money and the resulting time limitations can make it difficult to develop, expand and maintain social networks ${ }^{(69)}$.

Our design and analyses have a few limitations: we did not collect in a systematic manner any sociodemographic characteristics of the respondents (such as age, education, years in the USA, country of origin). This information would be helpful to understand possible differences in experiences by sub-population groups. We also did not directly assess mothers' perspectives about healthful eating and therefore cannot make any assumptions about diet quality. The strengths of our study include: (i) interviewing participants twice and holding an action workshop with all participants to delve deeper into their perceptions and experiences; (ii) verbatim transcription of all discussions to increase accuracy of the qualitative data and to aid in the interpretation and relationships between sub-themes and themes; and (iii) the use of participatory methods by including the community advisory board to assist in the interpretation of findings. These approaches maximize the rigour of the qualitative analysis.

In sum, mothers' food values for 'traditional' and 'healthful' foods influenced how they navigate the neighbourhood food environment. Mothers navigated the food environment to find quality and well-priced foods and beverages that they valued for their children. Food values were reinforced by pre-migration food customs, health professionals' advice and, in some cases, by the avoidance of family conflict and catering to child food preferences. The neighbourhood food environment could directly influence children's food preferences and often created conflict between what the child wanted to eat and the foods that mothers valued. Mothers in this 'food swamp' would like to be engaged in addressing the selection of foods offered in schools and in neighbourhood food venues to reflect the foods that they value.

\section{Acknowledgements}

Acknowledgements: The authors would like to thank the Community Advisory Board of the Avance Center for the Advancement of Immigrant/Refugee Health for their input in providing context to the study findings. They would also like to thank the mothers who participated in the study; Mrs Basmah Rahman, research associate at the Avance Center, and Rivera Group staff, who assisted with the logistics and coordination of the culminating workshop; and N. Ramos Torres and A. Colon-Rosado for assistance throughout this project and manuscript, including editing, translations and initial coding scheme. Financial support: This publication was supported by a grant from the Honey Nashman Center for Civic Engagement and Public Service at the George Washington University; and by the Centers for Disease Control and Prevention (grant/cooperative agreement number 5 U58 DP005819-03). Its contents are solely the responsibility of the authors. Conflict of interest: None declared. Authorship: U.C.-R. conceived the study, study design and analysis; led analysis of the data; contributed to interpretation; and led the writing and drafting of revisions. R.M.-R. contributed significantly to interpretation of results and writing. E.C. assisted with data analysis and contributed to writing and interpretation of results. I.M.R. led data collection. E.L.A. and M.C.E. contributed to revisions and interpretation of data, incorporation of photovoice methodology and theoretical application for findings. All authors contributed significantly to drafting the manuscript and revisions, and reviewed all drafts and the final manuscript. Ethics of buman subject participation: All instruments and protocols were reviewed and approved by the Office of Human Research of the George Washington University. All participants provided informed consent and express permission for audio- or videotaping during data collection activities.

\section{References}

1. Rodriguez CJ, Allison M, Daviglus ML et al. (2014) Status of cardiovascular disease and stroke in Hispanics/Latinos in the United States: a science advisory from the American Heart Association. Circulation 130, 593-625.

2. US Census Bureau (2008) 2008 National Population Projections: Summary Tables. Table 4: Projections of the Population by Sex, Race, and Hispanic Origin for the United States: 2010 to 2050. NP2008-T4. https://www.census.gov/ population/projections/data/national/2008/summarytables. html (accessed February 2017). 
3. Daviglus ML, Talavera GA, Avilés-Santa ML et al. (2012) Prevalence of major cardiovascular risk factors and cardiovascular diseases among Hispanic/Latino individuals of diverse backgrounds in the United States. JAMA 308, $1775-1784$

4. Wang YC, Gortmaker SL \& Taveras EM (2011) Trends and racial/ethnic disparities in severe obesity among US children and adolescents, 1976-2006. Int J Pediatr Obes 6, 12-20.

5. Ogden CL, Carroll MD, Lawman HG et al. (2016) Trends in obesity prevalence among children and adolescents in the United States, 1988-1994 through 2013-2014. JAMA 315, 2292-2299.

6. Heidenreich PA, Trogdon JG, Khavjou OA et al. (2011) Forecasting the future of cardiovascular disease in the United States: a policy statement from the American Heart Association. Circulation 123, 933-944.

7. Sallis JF \& Glanz K (2006) The role of built environments in physical activity, eating, and obesity in childhood. Future Child 16, 89-108.

8. Lovasi GS, Hutson MA, Guerra M et al. (2009) Built environments and obesity in disadvantaged populations. Epidemiol Rev 31, 7-20.

9. Larson NI, Story MT \& Nelson MC (2009) Neighborhood environments: disparities in access to healthy foods in the US. Am J Prev Med 36, 74-81.

10. Story M, Kaphingst KM, Robinson-O'Brien R et al. (2008) Creating healthy food and eating environments: policy and environmental approaches. Annu Rev Public Health 29, 253-272.

11. The Food Trust, The Reinvestment Fund \& Policy Link (2014) The Healthy Food Financing Initiative (HFFI): an innovative public-private partnership sparking economic development and improving health. http://www.healthy foodaccess.org/sites/default/files/HFFI\%20Fact\%20Sheet_four\% 20pager_100615.pdf (accessed September 2015).

12. DC Department of Health (2013) DC Department of Health and DC Central Kitchen partner to fight obesity with new mobile food cart program. http://doh.dc.gov/release/dcdepartment-health-and-dc-central-kitchen-partner-fight-obesitynew-mobile-food-cart (accessed June 2014).

13. Ortega AN, Albert SL, Chan-Golston AM et al. (2016) Substantial improvements not seen in health behaviors following corner store conversions in two Latino food swamps. BMC Public Health 16, 389.

14. Dubowitz T, Ghosh-Dastidar M, Cohen DA et al. (2015) Diet and perceptions change with supermarket introduction in a food desert, but not because of supermarket use. Health Aff (Millwood) 34, 1858-1868.

15. An R \& Sturm R (2012) School and residential neighborhood food environment and diet among California youth. Am J Prev Med 42, 129-135.

16. Shier V, An R \& Sturm R (2012) Is there a robust relationship between neighbourhood food environment and childhood obesity in the USA? Public Health 126, 723-730.

17. Sturm R \& Datar A (2005) Body mass index in elementary school children, metropolitan area food prices and food outlet density. Public Health 119, 1059-1068.

18. Powell LM \& Bao Y (2009) Food prices, access to food outlets and child weight. Econ Hum Biol 7, 64-72.

19. Lee H (2012) The role of local food availability in explaining obesity risk among young school-aged children. Soc Sci Med 74, 1193-1203.

20. Shier V, Nicosia N \& Datar A (2016) Neighborhood and home food environment and children's diet and obesity: evidence from military personnel's installation assignment. Soc Sci Med 158, 122-131.

21. Krukowski RA, Sparks C, DiCarlo M et al. (2013) There's more to food store choice than proximity: a questionnaire development study. BMC Public Health 13, 586.
22. Bleich SN, Jones-Smith J, Wolfson JA et al. (2015) The complex relationship between diet and health. Health Aff (Millwood) 34, 1813-1820.

23. DiSantis KI, Hillier A, Holaday R et al. (2016) Why do you shop there? A mixed methods study mapping household food shopping patterns onto weekly routines of black women. Int J Behav Nutr Phys Act 13, 11.

24. DiSantis KI, Grier SA, Oakes JM et al. (2014) Food prices and food shopping decisions of black women. Appetite 77, 104-112.

25. Stern D, Poti JM, Ng SW et al. (2016) Where people shop is not associated with the nutrient quality of packaged foods for any racial-ethnic group in the United States. Am J Clin Nutr 103, 1125-1134.

26. Cannuscio CC, Hillier A, Karpyn A et al. (2014) The social dynamics of healthy food shopping and store choice in an urban environment. Soc Sci Med 122, 13-20.

27. Rose DJ (2011) Captive audience? Strategies for acquiring food in two Detroit neighborhoods. Qual Health Res 21, 642-651.

28. Zenk SN, Odoms-Young AM, Dallas C et al. (2011) 'You have to hunt for the fruits, the vegetables': environmental barriers and adaptive strategies to acquire food in a lowincome African American neighborhood. Health Educ Behav 38, 282-292.

29. Zachary DA, Palmer AM, Beckham SW et al. (2013) A framework for understanding grocery purchasing in a low-income urban environment. Qual Health Res 23, 665-678.

30. Wang CC \& Pies CA (2004) Family, maternal, and child health through photovoice. Matern Child Health J 8, 95-102.

31. Wang CC (1999) Photovoice: a participatory action research strategy applied to women's health. J Womens Health $\mathbf{8}$, 185-192.

32. Wang C \& Burris MA (1997) Photovoice: concept, methodology, and use for participatory needs assessment. Health Educ Behav 24, 369-387.

33. Hergenrather KC, Rhodes SD, Cowan CA et al. (2009) Photovoice as community-based participatory research: a qualitative review. Am J Health Behav 33, 686-698.

34. Narayan KM, Boyle JP, Thompson TJ et al. (2003) Lifetime risk for diabetes mellitus in the United States. JAMA 290, 1884-1890.

35. Nielsen Scarborough (2015) Prince George's County Data [company data collected for George Washington University]. Retrieved October 2015 from Nielsen Scarborough Market Research Company database.

36. Scott MM, MacDonald G, Collazos J et al. (2014) From Cradle to Career: The Multiple Challenges Facing Immigrant Families in Langley Park Promise Neighborhood. Langley Park, MD: The Urban Institute, Prince George's County Public Schools and CASA de Maryland.

37. Luan H, Law J \& Quick M (2015) Identifying food deserts and swamps based on relative healthy food access: a spatio-temporal Bayesian approach. Int J Health Geogr $14,37$.

38. Rose D, Bodor JN, Hutchinson PL et al. (2010) The importance of a multi-dimensional approach for studying the links between food access and consumption. J Nutr 140, 1170-1174.

39. Andrade EL, Cubilla IC, Sojo-Lara G et al. (2015) Where PYD meets CBPR: a photovoice program for Latino immigrant youth. $J$ Youth Dev 10, 151002FA003.

40. Glanz K, Rimer BK \& Lewis FM (2002) Health Behavior and Health Education. Theory, Research and Practice. San Francisco, CA: Wiley \& Sons.

41. Bronfenbrenner U (1979) The Ecology of Human Development: Experiments by Nature and Design. Cambridge, MA: Harvard University Press. 
42. Bronfenbrenner U \& Ceci SJ (1994) Nature-nurture reconceptualized in developmental perspective: a bioecological model. Psychol Rev 101, 568-586.

43. Colón-Ramos U, Thurman ST, Burns H et al. (2016) Shaping our kids' diets: home and neighborhood. Results from photovoice exercise with low-income African American mothers living in a food desert. Presented at Experimental Biology 2016: Transforming the Future Through Science, San Diego Convention Center, San Diego, CA, 2-6 April 2016.

44. Birch LL \& Fisher JO (1998) Development of eating behaviors among children and adolescents. Pediatrics 101, 539-549.

45. Birch LL \& Davison KK (2001) Family environmental factors influencing the developing behavioral controls of food intake and childhood overweight. Pediatr Clin North Am 48, 893-907.

46. Gillespie AM \& Johnson-Askew WL (2009) Changing family food and eating practices: the family food decisionmaking system. Ann Behav Med 38, Suppl. 1, S31-S36.

47. Wallerstein N \& Bernstein E (1988) Empowerment education: Freire's ideas applied to health education. Health Educ $Q$ 15, 379-394.

48. Freire P (1973) Education for Critical Consciousness. New York: Seabury Press.

49. Bowen DJ, Barrington WE \& Beresford SA (2015) Identifying the effects of environmental and policy change interventions on healthy eating. Annu Rev Public Health 36, 289-306.

50. Penney TL, Brown HE, Maguire ER et al. (2015) Local food environment interventions to improve healthy food choice in adults: a systematic review and realist synthesis protocol. BMJ Open 5, e007161.

51. Neff RA, Palmer AM, McKenzie SE et al. (2009) Food systems and public health disparities. J Hunger Environ Nutr $\mathbf{4}$, 282-314.

52. Evans A, Banks K, Jennings R et al. (2015) Increasing access to healthful foods: a qualitative study with residents of low-income communities. Int J Behav Nutr Phys Act 12, Suppl. 1, S5.

53. Ayala GX, Elder JP, Campbell NR et al. (2001) Nutrition communication for a Latino community: formative research foundations. Fam Community Health 24, 72-87.

54. Hampl JS \& Sass S (2001) Focus groups indicate that vegetable and fruit consumption by food stamp-eligible Hispanics is affected by children and unfamiliarity with nontraditional foods. J Am Diet Assoc 101, 685-687.

55. Lindsay AC, Sussner KM, Greaney ML et al. (2009) Influence of social context on eating, physical activity, and sedentary behaviors of Latina mothers and their preschool-age children. Health Educ Behav 36, 81-96.
56. National Cancer Institute (2014) Health Information National Trends Survey, HINTS Brief no. 22. https://hints.cancer.gov/ docs/Briefs/HINTS_Brief_22.pdf (accessed November 2016).

57. Livingston G, Minushkin S \& Cohn D (2008) Hispanics and health care in the United States: access, information, and knowledge. http://www.pewhispanic.org/files/reports/91. pdf (accessed November 2016).

58. Connors M, Bisogni CA, Sobal J et al. (2001) Managing values in personal food systems. Appetite 36, 189-200.

59. Pollard J, Kirk SFL \& Cade JE (2002) Factors affecting food choices in relation to fruit and vegetable intake: a review. Nutr Res Rev 15, 373-378.

60. Story M, Kaphingst KM \& French S (2006) The role of schools in obesity prevention. Future Child 16, 109-142.

61. Evans A, Chow S, Jennings R et al. (2011) Traditional foods and practices of Spanish-speaking Latina mothers influence the home food environment: implications for future interventions. J Am Diet Assoc 111, 1031-1038.

62. Au LE, Rosen NJ, Fenton K et al. (2016) Eating school lunch is associated with higher diet quality among elementary school students. J Acad Nutr Diet 116, 1817-1824.

63. Chatterjee A, Daftary G, Campbell M et al. (2016) 'Can't we just have some sazon?' Student, family, and staff perspectives on a new school food program at a Boston high school. $J$ Sch Health 86, 273-280.

64. Callister LC, Beckstrand RL \& Corbett C (2011) Postpartum depression and help-seeking behaviors in immigrant Hispanic women. J Obstet Gynecol Neonatal Nurs 40, 440-449.

65. Ornelas IJ \& Perreira KM (2011) The role of migration in the development of depressive symptoms among Latino immigrant parents in the USA. Soc Sci Med 73, $1169-1177$.

66. Alvidrez J (1999) Ethnic variations in mental health attitudes and service use among low-income African American, Latina, and European American young women. Community Ment Health J 35, 515-530.

67. Parrado EEA, Flippen CA \& McQuiston C (2005) Migration and relationship power among Mexican women. Demography 42, 347-372.

68. Viruell-Fuentes EA \& Schulz AJ (2009) Toward a dynamic conceptualization of social ties and context: implications for understanding immigrant and Latino health. Am J Public Health 99, 2167-2175.

69. Hurtado-de-Mendoza A, Gonzales FA, Serrano A et al. (2014) Social isolation and perceived barriers to establishing social networks among Latina immigrants. Am J Community Psychol 53, 73-82. 